\title{
Landscape Sustainability of Architecture in Fernando Menis's Work: A Sensitive Design Rooted in Volcanic Nature
}

\author{
Simona Calvagna \\ Department of Civil Engineering and Architecture, University of Catania, Via Santa Sofia 64, 95123 Catania, Italy; \\ simona.calvagna@unict.it; Tel.: +39-095-738-2517
}

Received: 11 September 2020; Accepted: 12 October 2020; Published: 20 October 2020

check for updates

\begin{abstract}
The many declinations of the idea of sustainability in architecture concern different disciplinary areas as well as all phases of the construction process. Alongside the more established categories of the sustainability of materials used and the technical construction processes and economic investments mobilized, there are now new facets of the idea of sustainability. They affect the impact that architecture can have on communities in terms of social relations and quality of context of life. This work explores the idea of landscape sustainability of architecture, understood as the ability of man-made interventions to belong to the context and the inhabitants, while promoting forms of alliance with the ecosystems at multiple spatial and temporal scale. Starting from the analysis of some trends in contemporary architecture that deals with these problems, the research identifies the volcanic environment as a terrain for exploration, with particular interest in its natural characteristics and dynamic interactions with anthropic contexts. After choosing the region of Macaronesia as a case study, the research focuses on the work of Fernando Menis. As an architect from the Canary Islands, he has developed his own modus operandi which, while rooted in its original context, is inspired by principles of social, cultural, and landscape sustainability of architecture that are valid today everywhere. The objective of this work is therefore to draw a reflection from his architectural poetics, with the intention of outlining the features of a possible contemporary design posture based on principles of landscape sustainability.
\end{abstract}

Keywords: sustainable architectural design; landscape dimension of architecture; landscape sustainability; sensitive architecture; volcanic landscape identity; Canary Islands; Fernando Menis Arquitectos; Artengo Menis Pastrana

\section{Introduction}

\subsection{Technology Versus Humanity. What Kind of Progress in the Global Era?}

"While cities in the global North are so heavily invested in 20th-century materials and techniques that a volte-face is difficult, the global South has a unique opportunity to leap ahead and maybe even led by example. The lack of capital, harsher climates and need to preserve a sense of community are stimulating factors that are producing new proposals for a more sustainable future. This is something to celebrate and look forward to. So, if the early 20th century was about technological advances, breaking from the architectural past, and the promises of the International Style, the 21st century might be shaping up to take us back to the humanity of architecture, not its technical prowess." [1]. This passage from a more general reflection by architect Mariam Kamara, Nigerian in origin, overturns the dominant logic of the idea of progress in architecture, reducing the importance of technology in favor of humanity and highlighting the potential of marginal places of the world as "modelholders" for the sustainable design of today. 
Architecture is called upon, particularly in the most fragile contexts because they are marginal with respect to the flows of the dominant economy, to suggest ways of inhabiting the planet that are increasingly attentive regarding social, environmental and ecological relations. This is all the more true today, in the midst of the planetary health emergency caused by the Covid-19 pandemic, which has created a crisis in the model of economic and social development based on industrialization followed by the most advanced countries of the world. This recent experience reinforces the idea that innovation in architecture should be aimed at restoring the balance between man and nature compromised over the last 50 years. Proposing models in which contextual buildings, capable of producing democratic, healthy, socially, and economically sustainable spaces, architecture now has to combine local and global, tradition, and innovation. The humanity of architecture, invoked in Miriam Kamara's initial reflection, recalls what Lucien Kroll calls humanitude: the active quality of a milieu designed to encourage inhabitants-actors to spontaneously undertake humanization initiatives at every stage of their lives $[2,3]$.

\subsection{Sustainability of Architecture: the Importance of Beeing Sensitive}

A contemporary sustainable approach to architecture must therefore seek to foster a greater sensitivity of architecture towards people's uses, to the meanings they attribute to places and to climate and local resources. Such an approach should help people get rid of the superstructures of the logic of consumption, aiming at the simplicity of being in the world [4]. The cultural posture underlying a sustainable approach to design moves from an awareness of the end of anthropocentrism [5]; architecture cannot simply be man's instrument for inhabiting the world but must be understood as a global tool for the sustainable existence of the world itself. It must integrate into it, as is the case, for example, of vernacular architecture [6], or more generally of architecture without architects [7], whose paradigms still provide innovative elements to be developed through a dialogue with new technologies. In this perspective, the landscape dimension of the architectural intervention is particularly important. Taking this aspect into consideration in the design process entails both a greater attention to the concreteness of experience of lived space and a deep and rigorous recognition of the genius loci, in order to ensure that the projects truly belong to the places they are created for.

\subsection{Landscape Sustainability of Architecture}

The idea of landscape referred to is not reduced to the visible perception of places, but also has a physical materiality, linked both to nature as organized in space and to the transformations impressed on the environment by human activities [8]. Thus, the landscape impact of an architectural intervention cannot be measured only in perceptive terms, but it is also necessary to take into account the physical relationships between architecture and ecosystems as well as those between new built spaces and the societies that interact with them. It is therefore a complex and multidisciplinary assessment, as the very notion of landscape enshrined in the European Landscape Convention implies [9]. In recent decades, a seam of research on landscape sustainability on the territorial scale has developed, focusing more on the technical-ecological aspects than on the socio-cultural and theoretical aspects [10]. In order to pursue a desirable holistic vision of the sustainable landscape project [11] it is useful to consider this seam of research as a framework for the research on architectural design today. Little has been investigated regarding the contribution that architectural design can make-not only in terms of energy and building construction, but also in spatial, cultural, and symbolic terms-to landscape sustainability. The main problem is that disciplinary fields of architectural design research and landscape sustainability research do not yet interact, as shown in the following literature background.

\subsection{Phenomenological Research on Architecture: a Landscape Approach to Architectural Design}

However, post-modern architectural research over the last 50 years has produced reflections and experiments that can be traced back to a landscape approach to architectural design. These are reflections interested in the material and corporeal dimension of architectural space, in the relational and 
experiential aspects of architecture, and in the respect of place and context by the built intervention. This line of research feeds a phenomenological current of architecture [12] to which can be traced, albeit with different outcomes and modalities, the works and the thought of some personalities of the contemporary panorama. If, on the one hand, Steven Holl's work has a precise and explicit interest towards the phenomenology of architecture [13,14], on the other hand authors such as Alvaro Siza, Peter Zumthor and Tadao Ando have also developed lines of design research close to phenomenology [12]. However, it can be observed that best practices in this sense do not necessarily have to be linked to important names. Today, in those very marginal places less pressed by globalization and dominant thought, there emerge experiences of a widespread architectural sensibility animated by a profound search for "humanization" and "contextualization" of architectural intervention.

\subsection{Why Macaronesia and Fernando Menis Work as Case Study?}

Significant in this sense is the case of Macaronesia, a region of volcanic origin made up of the five archipelagos beyond the Strait of Gibraltar (Azores, Canaries, Madeira, Cape Verde, and Salvage) where it is possible to trace a contemporary architectural trend aimed at the integration between architecture and nature that unites the sensibility of different designers working in the area. The design approach object of interest for the present work can be briefly described through the words of Marguerite Yourcenar: "To build is to collaborate with earth, to put human mark upon a landscape, modifying it forever thereby." [15]. The lava soil of Macaronesia thus becomes the characterizing element of the genius loci that is taken up by architecture. How does this happen? Is it possible to identify best practices from which to derive principles to extend to other contexts? In order to answer these questions, it will be useful to look at the work of Fernando Menis, a Canarian architect working mainly in Tenerife but with projects in various parts of the world. By analyzing the entire work and selecting significant projects and achievements, it is possible to see that the modus operandi developed by this architect manages to reconcile the interest in the identity of his original context with the demands of global architectural sustainability in different contexts.

The main purposes of this article are to elucidate relations between architecture, landscape, and sustainability and to focus on best practices of landscape sustainability of architecture that can be found in marginal places. To this end, after defining a theoretical frame of reference capable of linking architecture design with landscape sustainability, the research examines a selection of contemporary architectures in Macaronesia, considered exemplary as a marginal context, and then focuses on the work of Fernando Menis. In this way, it is intended to highlight, starting from the study of Menis's work, how practices and principles of landscape sustainability of architecture elaborated in marginal contexts can generally be valid to address architecture and landscape design in the global era.

\section{Literature Background}

\subsection{Architecture and Landscape towards Sustainability}

Architecture necessarily has a landscape dimension that can no longer be neglected today. Architecture, as an artifice, was originally conceived culturally in dialectical opposition to nature. Today, however, in the light of the profound changes that human activity has produced on the environment, we can no longer afford to consider architecture as an isolated artificial object in opposition to nature. It is necessary to imagine it integrated with its context (natural or urban) and in harmony with its inhabitants. To do this, it is not enough to conduct architectural research at the scale of the building, but it is also necessary to look at other fields of research at the territorial and landscape scale. At the moment the research on architectural design and landscape sustainability do not dialogue through the most widespread research platforms. The respective disciplinary fields are not in communication, but comparisons can be made. Architecture can take an active role in the pursuit of the dynamic balance between human development and the protection of environmental resources, advocated by the 1987 Brundtland Report [16]. The landscape sustainability of anthropic 
transformations has been rethought in research in the sector of recent decades not only in ecological terms, but in a multidimensional perspective able to involve all aspects of human wellbeing in harmony with nature [17]. In the disciplinary debate around the definition of a possible science of landscape sustainability, the intense link between human wellbeing (understood as the satisfaction of survival, psychological, and spiritual needs) and the reference themes of landscape ecology (Ecosystem Services and Biodiversity and Ecological Processes) emerges, opening new perspectives of contamination between disciplines dealing with sustainability.

Musacchio (2009) [18] identifies six different dimensions of landscape sustainability (6 E's): environment, economy, equity, esthetics, experience, and ethics, calling for an integrated and holistic perspective in the debate on sustainable development [11]. Architecture, as a form of cultural expression of a territory, can and should be considered as an important component of a sustainable landscape, and the sustainability of architecture cannot therefore be without a landscape dimension. As is the case with the landscape scale, it is certainly reductive to think that, moving to the scale of architecture, the sustainability of architecture can only be measured through technical standards [19]. It is necessary to take into account the real human needs, the dignity of living, the integration between designed spaces, inhabitants and places. Also, when considering the sustainability of architecture from this point of view, the contradiction in terms of the expression "Sustainable Development" emerges. As shown by the visionary experiment in the village of New Gourna, carried out in Egypt in the 1940s by Hassan Fathy [20], settlement models compatible with the quality of life of a given place often come not from technological progress but from vernacular architecture, capable of responding naturally to the needs of communities better than other codified models. Originating from the relationships between people and places, vernacular architecture should be interpreted as the result of cultural actions, customs, and traditional knowledge. The anchoring to places determines a sort of hybridization between architecture, nature, and construction [21]: The work of man and his technological capabilities are put at the service of a human worldview in harmony with nature. For this reason, today, many projects inspired by the principles of sustainability tend to combine technological innovation with the heritage of techniques, forms, and settlement methods of vernacular architecture [22]. The earthen schools and houses in Burkina Faso designed by Francis Kéré are today an example of how the landscape sustainability of architecture, obtained through the combination of traditional building techniques and local materials with modern technologies, is closely linked to its social sustainability, obtained through the design of spaces that encourage participation, communication, and mutual enrichment [23].

\subsection{Phenomenological Architecture and Landscape Sustainability}

The concept of critical regionalism investigated by Kenneth Frampton [24] can also be traced back to the idea of landscape sustainability, as it underlines the need to put at the center of architecture the ability to resonate with the climatic, topographical, historical characteristics specific to places, operating a sort of resistance to global homologation trends. This follows in the footsteps of the reflections of Christian Norberg-Schulz at the end of the 1970s. With the essay Genius Loci [25], he fed the cultural demands of the phenomenological current of architecture that, subsequently, has expressed a critical response to the Modern Movement based on the search for the distinctive features of the place through architecture understood as a sensitive experience. Starting from the last decades of the 20th century, through the phenomenological approach, many architects have cultivated a relational sensitivity to the context and the user, producing architecture that is sustainable in its landscape dimension. Among the several souls present in this current, different postures emerge. Some of them are supported by consolidated and enduring careers: Tadao Ando proposes architecture understood as "the art of articulating the world through geometry", generating concrete spaces made up of history, culture, milieu, topography, and cities. "A place is not the absolute space of Newton's physics-a universal space-but a dense and heterogeneous space, bearer of meaning, arising from shintai" [26]. With this Japanese term, difficult to translate, Ando indicates the corporeity with which the human being inhabits the world; placed at the center of his experimentation, the shintai is the key element with 
which, anchoring architecture to concrete experience, spatiality and place, Ando opposes the processes of homogenization and trivialization of the world, pursuing the intention of "creating symbolic spaces based on concreteness" [26]. The work of Alvaro Siza can also be interpreted with the same key. In his buildings (think, for example, of the Serralves foundation in Porto or the swimming pools in Leça de Palmeira) architecture intertwines with open space without a clear delimitation between inside and outside, generating open forms that include, in their use, the heterogeneity of the surrounding context, near and far, incorporating it into the experience of architecture [27]. For Kengo Kuma, instead, architecture should simply be "erased". By proposing a reversal of the vision, he suggests trying to look at architecture from the inside, to avoid conceiving it as an object, as in the case of the Kiro-San observatory project in Japan: "Instead of placing an object on top of the mountain, I carved a slit in its top. [...] Inside the crevice there are a series of areas connected by paths. Each of these has a unique relationship with the environment, i.e., in each place the landscape is set in a frame in a particular way. People do not see an architectural object, but they have a sequential experience" [28]. A further piece can be added to this brief comparative reflection, recalling the thinking behind the work of the Irish firm Grafton Architects. Winners of the Pritzker Price in 2020, Shelley McNamara and Yvonne Farrell express in their manifesto Freespace, drawn up on the occasion of the Venice Architecture Biennale in 2018, their idea of architecture based on an "extended" sustainability that includes aspects related to the perception and use of architectural space. Architecture must be "generous in spirit" by offering free spaces to those who use them, it must emphasize the gifts given by nature (light, sun, moonlight, air, force of gravity), cultivate, and promote a meaningful contact between people and space, considering "the Earth as a Client", and therefore assuming deep and serious long-term responsibilities [29]. A key element of the landscape sustainability of a work is, ultimately, the capability to build relationships of different nature between the work itself, the environment that welcomes it, and the people who live there.

\section{Materials and Methods}

\subsection{Objectives and Methodology}

Starting from the hypothesis that the landscape sustainability of architecture is intensely correlated to its capability to build relationships between environment, artifacts and people, this paper questions the ways in which architecture fits sustainably into a landscape, taking the Macaronesia region as a case study.

After connecting the sustainability of architectural intervention with the sustainability of the landscape through the literature background, the aim is to experiment with a method of analysis of architecture capable of highlighting its landscape dimension. The study chooses to deal with marginal contexts because they are less subject to the processes of homologation of landscapes due to globalization, and therefore often retain authenticity. Subsequently, they can be home of best practices for the design experimentation of landscape sustainability of architecture. The research focuses on the analysis of a specific context, the Macaronesia region, whose interest lies in the intense link between the environments built by man and burgeoning volcanic nature. Exemplary projects carried out in the different archipelagos are examined, highlighting the common attention to volcanic ground. This is understood both as an identity element of the landscape with which the architectural project has fruitful relations, and as a bulwark of resistance against the threats of homogenization and trivialization of the landscape coming from the trends of cultural globalization. These materials are useful to facilitate a situational interpretation of the work of the Canarian architect Fernando Menis, who is considered exemplary from the point of view of landscape sustainability because of the characteristics highlighted below. The comparative study of a selection of Menis's projects, realized and not, is based on an extrinsic methodological approach, in order to highlight the connections between project, architecture, context and society, which are crucial for the hypotheses that are to be verified here. 
The information was collated from articles in scientific architecture journals (according to the Italian Anvur classification), monographs, and peer review journals (limited to the topic of landscape sustainability). Not all articles are present in the most widespread scientific databases available online, so a first result of the research was to collect and compare these materials. The material collected has been integrated with widely consulted websites in the field of architectural design, which animate the debate on contemporary architectural culture [30-32]. The bibliographical research has provided a limited but indispensable documentation basis for the subsequent interpretive analysis. An essential contribution was provided by a direct meeting with Fernando Menis and the dialogue with his office. This made it possible to enter without interposed filters into his design method.

The projects analyzed were selected on the basis of their representativeness with respect to the theme of landscape sustainability. Although the entire work of Menis is permeated by a general concern with this theme, the projects chosen are those founded on the leading idea of interweaving relationships with the context and communities.

The interpretive analysis has been carried out by directly analyzing drawings, photos of models and of realizations, and texts written by the author, integrated by conversations. These materials were considered as primary sources, on which a critical-hermeneutical reflection was carried out, in a constant comparison with the bibliographical sources consulted. For each project, the design ideas that shaped the interior spaces and architectural configurations were highlighted. A common thread between the various ideas is then traced, highlighting how they complement each other, in search of an alliance with the context and respect for the human dimension.

The works analyzed have been gathered around three federative research themes, considered expressive of the evolutionary trajectory of the main concerns underlying Menis's project. Those themes outline how architecture becomes a tool to weave relationships, to fit sustainably into a landscape. Ultimately, the synthesis of the analyzed topics can be considered as a matrix of keywords for the definition of a holistic vision of the landscape sustainability of architecture.

\subsection{Architecture and Landscape at the Margins of the World: the Macaronesian Region}

Macaronesia is characterized by the common igneous origin of its lands and the nebulous knowledge of the myth that surrounds it. In fact, the extremely dynamic physical conditions due to ocean currents and winds (trade winds and monsoons) generate complex mosaics of climates and promote biological diversity, with surprising differences between the desert biome of Cape Verde and the hyper-humid biome of the Azores [33].

Because of their disposition to form a sort of "arch" beyond the Pillars of Hercules (the Strait of Gibraltar) and the generosity of their nature, they have been considered in the past as extreme frontiers of the world and identified with mythological and legendary places. With their real discovery between the 13th and 14th centuries by European explorers, a progressive cultural differentiation was achieved. The four inhabited archipelagos (the Salvage Islands are deserted) have in fact experienced different economic and social developments, linked to the dynamics of colonization they underwent - the Canaries under Castilian influence, Madeira, the Azores, and Cape Verde, under the Lusitanian influence. The landscapes of Macaronesia therefore, as the numerous sites protected by UNESCO in various ways also highlight, preserve a heritage that is both naturalistic-environmental and historical-cultural. Today, the archipelagos of Macaronesia are both destinations of mass tourism and marginal places, where the wildest nature is sheltered from the main trajectories of homologation. Macaronesia therefore is a context of study whose contradictions constitute fertile ground for the present research.

Although in the past there has been no lack of urbanization processes that were inattentive to the peculiarities of these territories, it is possible to highlight a marked sensitivity regarding building transformations, sometimes even innate and spontaneous, resulting from a widespread idea of landscape sustainability. This can be translated into the importance given to the (volcanic) ground in the achievements of architecture and landscape, as is already visible in the most basic form of land 
occupation, which is agriculture. Although, in the Canaries, this can be traced back to the persistence of the Aboriginal culture of the Guanches, for whom care and contemplation of the environment was an integral part of life, the archipelago of the Azores also presents important examples. Here, the landscape of closed fields (bocage) is one of the most beautiful in the world. The soil is punctuated by an orderly network of flowering barriers or walls, which, adapting to geomorphological discontinuities, show the industrious work of man in inhabiting the earth. The wine-growing and wine-producing landscape of the island of Pico is an exemplary declination: Here, in addition to the weaving of the dry-stone walls, there are also manor houses, cellars, warehouses, churches, to form the complex agricultural landscape, covering 987 hectares and marked as World Heritage site [34]. The small Visitor Center for Gruta das Torres, a 5-km-long lava tunnel classified as a regional natural monument in 2004, is part of this context. The building, designed by Sami Arquitectos in 2005 (Figure 1a), provides an entrance to the natural cavity. It establishes a connection between the underground naturalness of the curved forms of the cave and the artificiality of the network of walls that weave the surrounding landscape, through the use of lava rock variously composed in the perimeter wall $[35,36]$. This small-scale architecture shows how volcanic soil can constitute a local identity element to be used in the project as a material, sensory and spatial tool to determine atmospheres, relationships and new forms of living.

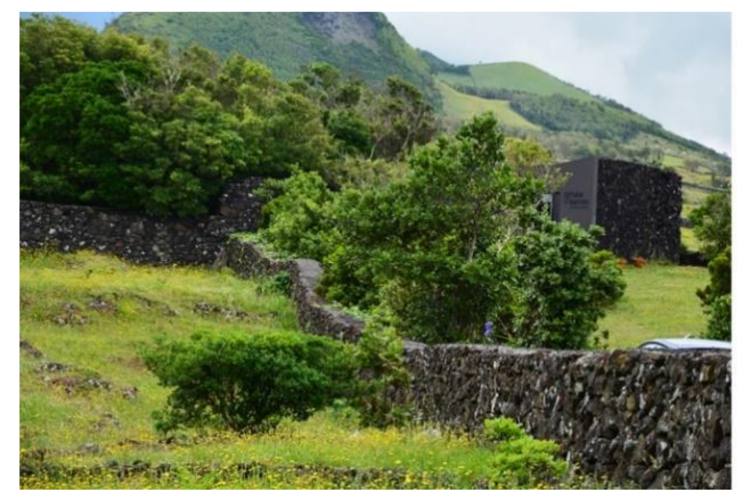

(a)

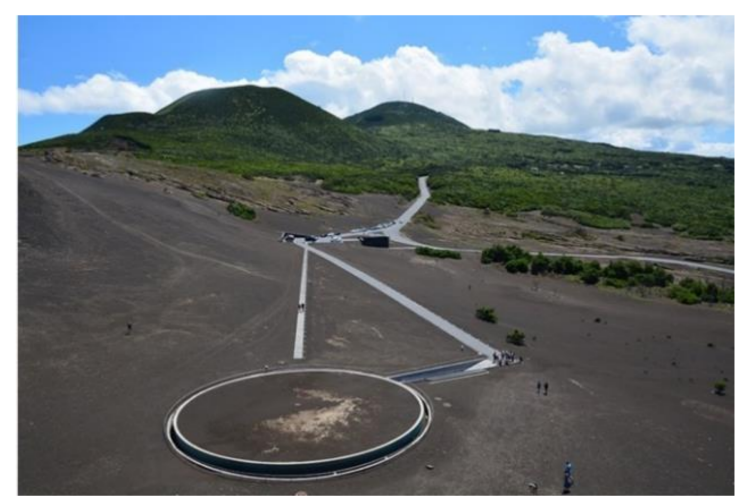

(b)

Figure 1. (a) Visitor Center Gruta das Torres, Pico Island (Azores), Sami arquitectos 2005; (b) Capelinhos Volcano Interpretation Centre, Fajal Island (Azores), Nuno Ribeiro Lopes 2008. Photo credit: Anna Maria Atripaldi.

Its importance in this sense was affirmed in the 1960s in Lanzarote by the militant artist César Manrique (1919-1992). He proposed an alternative model to the mass tourist exploitation of the island, transforming it into a laboratory of social and political consciousness. Through his art, the extreme volcanic environment, until then not considered attractive, was given new meanings and values. Emblematic of this new point of view on Lanzarote is its Jardin des Cactus. Inaugurated in 1990 in an old abandoned quarry immersed in opuntia cultivations, it houses a spectacular collection of succulent plants that settle between the terraces and the volcanic ash surfaces, reinventing new forms of peaceful coexistence with the volcanic environment [37]. Bringing the same interest to the construction of his house-foundation since 1968, Manrique adapts some small fragmented volumes to the folds of the ground, arranged with a Cartesian rigor that opposes the organic geometries of the natural caves under the house transformed into living rooms, gardens and swimming pools [38]. This lyrical approach to volcanic ground goes hand in hand with the necessary consideration of its dynamism and destructive power. In the case of the archipelago of the Canaries, disaster is an acquired and consolidated fact whose memory recalls the phenomena that shaped the landscape and gave it a precise identity. This translates into a rootedness of the architecture on the ground, of which destructive power is only memory. For the Volcano Interpretation Centre, however, built between 2005 and 2008 in Fajal, in the Azores (Figure 1b), things are otherwise. An impressing eruption of the Capelinhos submarine volcano 
between 1957 and 1958 radically transformed the landscape and orography of the island, adding new land to the coastline. The architecture thus confronts the memory of the disaster in a direct way, at a close temporal distance [39]. To give the utmost importance to the memory of the event (new landscape and the ruined lighthouse) the new building designed by Nuno Ribeiro Lopes is entirely underground. Nevertheless, it has a great impact without being really visible: The project appropriately reconciles the physical, natural, and immaterial heritage of the island, enhancing the genius loci through a unitary intervention in which the architecture merged with the landscape dissolving into it [40].

\subsection{Fernando Menis}

The overview of contemporary architecture and landscape in Macaronesian region helps to introduce the figure of Fernando Menis. His work, from the beginning to maturity, shows that starting from a design approach linked to the context and inspired by local landscapes, it is possible to elaborate codes of practice and rules to apply in other contexts to pursue the landscape sustainability of built interventions. Fernando Menis, after studying architecture in Barcelona, returned to Tenerife in the 1980s to establish his first firm together with the two associates he worked with until 2004-Artengo/Menis/Pastrana (AMP). He then continued on his own, dividing his time between the two offices in Valencia and Tenerife and starting to work abroad. He received prestigious international awards for his work, and his projects and models are exhibited in galleries and museums of international relevance. He is present in the most important international events related to architectural culture and he is invited to give lectures and conferences around the world. He is probably the most important living Canarian architect.

A search for articles about Menis work in the online catalogue of the RIBA Library produces more than 80 records between monographs and articles in architecture journals (most of international scientific relevance), in a time span ranging from 1993 to 2017. This confirms the interest raised by his architectural experimentation. A significant number of these articles have been collected and compared during the work of analysis.

\section{Results}

\subsection{The Work of Fernando Menis: A "Geological" Architecture between Local and Global}

The aim of this section is to deepen the analysis of the work of Fernando Menis. From the very first works with the AMP group, Menis has always known how to combine his personal vision of architecture-imbued with a design culture that can be traced back to the lessons of the Masters of the Modern Movement-with the genius loci of the Canary Islands. In fact, his thought and work cannot be fully understood unless they are placed in that precise context in which he was born, grew up, and works. The Canaries, as already mentioned, have influences from European, American, and African culture; from a geographical point of view, however, they are an archipelago in the ocean, with a majestic, sometimes hostile nature that dominates all human affairs, imposing a continuous relationship with it. If there are islands, such as Lanzarote or La Gomera, where nature continues to dominate over human settlements, in Tenerife, since the 1970s, especially on the southern coast with the construction of the second airport, there has been a construction boom in mass tourism facilities that has led to the trivialization of landscapes, once marked by arid moors dotted with fishing villages. In contrast to this widespread trend, Menis has distinguished himself for his poetics of primordial forms that have evolved, for over 30 years, in dialogue with the volcanic landscapes of his native island [41]. At the same time, his buildings, although they may recall natural objects in themselves, almost extracted from the geological and monolithic strata of the island, resonate profoundly with the traditions of European architectural culture. His architectural design experimentation constitutes an ongoing research that attempts to find solutions to the fragilities of 21st century models of global economic development. Since its first realizations, Menis has expressed an acute sensitivity towards the Canarian genius loci, demonstrating a high level of assimilation of the peculiar environmental characteristics without ever 
evading the expressive needs of architecture [42]. His is an endemic modernism: the influence of Frei Otto's holistic thinking and methodology is mixed, in his work, with a personal sensitivity to listening to nature and landscape [43].

Menis's architectural thought is analyzed in order to highlight the features that can be traced back to a general idea of landscape sustainability. To this end, three design research themes that guide precise ways of processing and configuring his works are identified.

The first issue with which Menis tends to achieve landscape sustainability is the constant search for the sensoriality of spaces. By focusing on the experience of architectural space, Menis aspires to govern the relationships between architecture, the user, and the landscape through the control of sensitive space, both at the scale of the building and at the scale of the context. The second major theme of Menis's approach to landscape sustainability is the relationship between architecture, community life and local economic development. Architecture must promote the harmonious coexistence of communities in their landscape and be constructed with local forces and materials, reinvented in an innovative way. The third theme is the influences of ecological issues in architectural design. If landscape sustainability concerns also the dynamic balance between human development and the protection of environmental resources [16], architecture can contribute effectively to preserve the landscape from the depletion of resources and can even become an active part for the production of energy useful for human life. The three themes are developed below by collecting a selection of exemplary projects, analyzed through the following keywords: Space, materials and landscape; architecture, community, identity; architecture and environment.

\subsection{Space, Materials and Landscape}

The first theme concerns the relations between space, materials, and landscape. Menis's work is sensorial, tactile, and strongly based on materials and their textures. Traditional materials and construction techniques are reinterpreted in an unconventional way, favoring innovation with a reduced impact on the environment [44]. Proceeding by plastic modelling of the volumes, the living spaces are obtained by excavations and fractures; then, the volumes are inserted into the landscape, adapting to the conditions. The architectures are intended as new artificial topographies, whose raw materiality contributes to emphasize the physical, sensory, and symbolic correspondence between nature and artifice. In the Olympic Stadium of Athletics (2004-2007), designed with AMP arquitectos, the construction is conceived as a telluric gesture, a crater that reintroduces into a peripheral urban fabric the geology that has now been obliterated by human settlement (Figure 2). The intervention seeks integration with urban life by taking the form of a topographical reorganization, a monumental presence that constitutes a landmark while dissolving into the landscape.

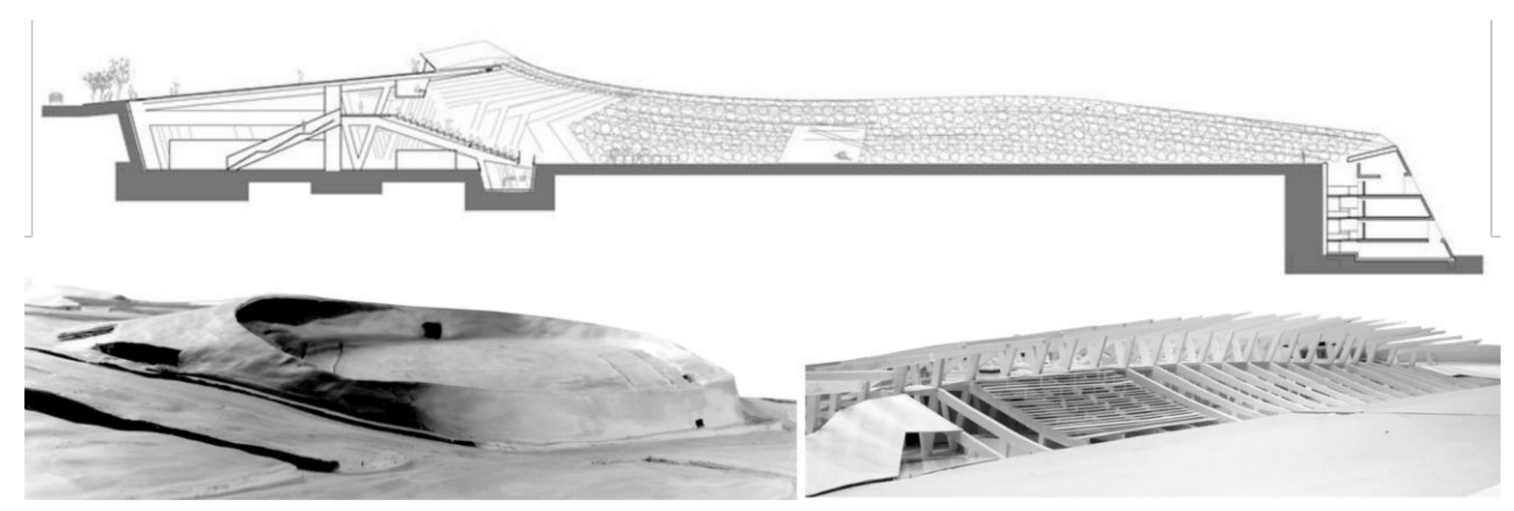

Figure 2. Olympic Athletics Stadium, Tenerife, Artengo Menis Pastrana 2004-2007. Section and study models. Photo credit: Fernando Menis

These elements of integration in the context are combined with the pursuit of the optimization of environmental orientation, the control of wind and natural energy, as well as the importance of 
the visual field for the 4,000 spectators, all characteristics of a broad idea of sustainability [45]. In the Botanical Garden of the Discovery of America (1997-2002), on the island of La Gomera, it is not possible to distinguish the building intended as a visitor center from the access routes, the retaining walls delimiting the site downstream, or the terraces overlooking the landscape: The built intervention is a single gesture that blends in with the surrounding terraced agricultural landscape. The building gives access to the garden below through a system of ramps and stairs embedded into the mighty wall parallel to the road, breaking down into measured volumes that recall the texture of cultivated plots on the irregular morphology of the ground [46].

The project of the Auditorium of Pajara (2008), on the island of Fuerteventura (not realized) is another example where the building is designed by digging and shaping the ground, so that the whole set of volumes can be perceived as a set of "clods" detached from the ground. The textures and colors of the project respond directly to the colors and elements of the surrounding environment: To achieve this, the concrete will be mixed with pigments obtained from the existing soil and stones on site. Natural light, appropriately dosed and directed, plays a crucial role in the definition of telluric spatialities. Descending mainly from above, it produces evocative effects making the interior spaces almost mystical and accentuating the sense of hollowed-out spaces. Emotional light is also the main ingredient in the project of the Holy Redeemer Church (1997-2002) at La Laguna (Figure 3). Light generated by the strategically positioned engravings takes on a narrative meaning, accompanying the different liturgical functions and marking the spaces dedicated to them. In this project, which has been difficult to carry out due to limited financial resources, the dialogue with the context that characterizes the landscape sustainability of Menis's works is enriched by a further facet. The anchoring to the place is a social necessity, rather than a perceptive and visual one: Located in a problematic suburb, the church built by Menis responds to the urgent need for a place of worship and aggregation with a primitive presence that seems to pre-exist on the periphery itself. With its introverted form consisting of four sculptural volumes juxtaposed in a bumpy manner, the building is a sort of ancient ruin that attempts to gather the residents around the Canarian genius loci.

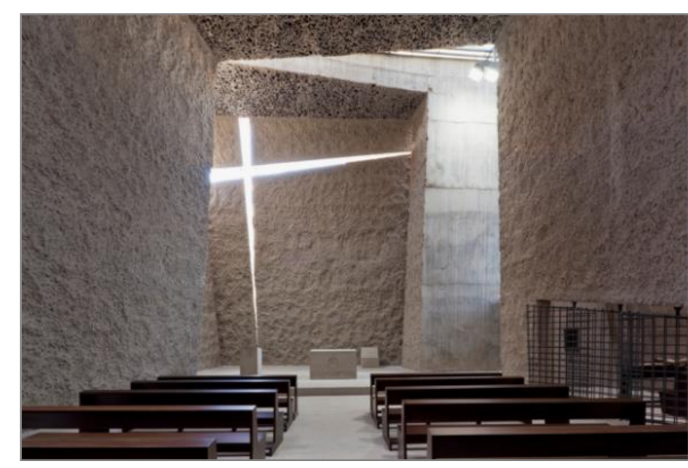

(a)

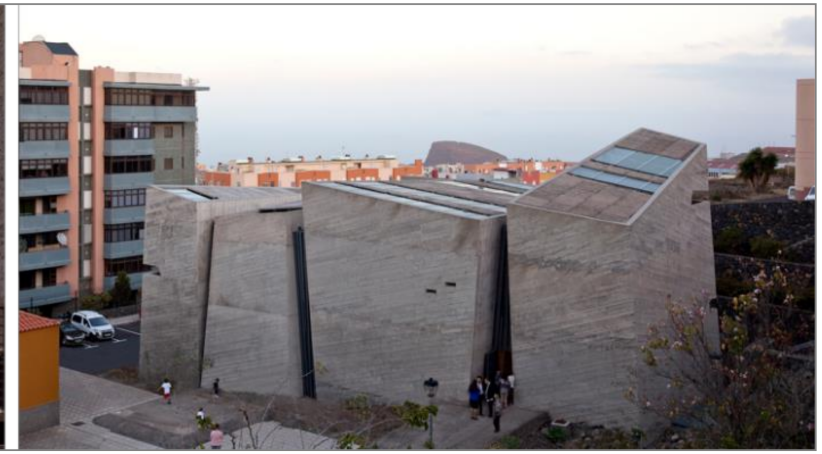

(b)

Figure 3. The Holy Redeemer Church, La Laguna, Fernando Menis 1997-2002. Interiors (a) and external view (b). Photo credit: Simona Rota.

\subsection{Architecture, Community, Identity}

These last considerations introduce the second major theme of Menis's approach to sustainability, namely the relationship between architecture, community life and the economic development of local societies. The promotion of the local economy is pursued by protecting the cultural and historical characteristics of the context, considered to be bearers of economic as well as patrimonial values; the project aims to qualify the framework of people's lives, serving the needs of the settled community and participating actively in the local economy. The design choices are commensurate with the available resources and tend to enhance construction technologies and production of local materials, combining them with innovative or experimental processes capable of renewing their interest. The criticality 
of the long gestation times of the projects is often converted into opportunities for the maturation and involvement of stakeholders in the implementation processes. Menis's projects seem capable of transforming this inertia into potential energy that erupts at the moment of realization, like the dramatically sculptural landscapes of the Canaries. A constant concern of his work of the last 10 years seems to be to pursue a real harmony between the lives of the inhabitants of the islands of the archipelago (so different in microclimatic and economic conditions) and at the same time to develop a sustainable infrastructure for tourism. Thus in the project for the Square and the Sacred Museum in Adeje (2007-2010 for the Square, the Museum is currently being completed) Menis aims to provide a socializing space for residents and tourists without having to compromise with the stereotypes of mass tourism of the southern coast of Tenerife, at the limit of which the intervention is situated (Figure 4). The public space designed within the small town of Adeje aims to enhance its authenticity and its value as a bastion of culture and tradition, through an almost invisible, largely underground intervention that tends to reconnect the old town with the powerful natural landscape that surrounds it. The volume proposed sectorizes Plaza de España, creating an intimate square, closer in character to the urban landscape and another which is open and sits in the landscape like a natural auditorium [47]. The buildings and new topographies propose themselves as cultural attractions capable of promoting economic growth based on alternative activities to those offered for mass tourism on the coast. This project is emblematic of the design posture that Menis has developed over time and which has paved the way for projects outside its territory of origin.

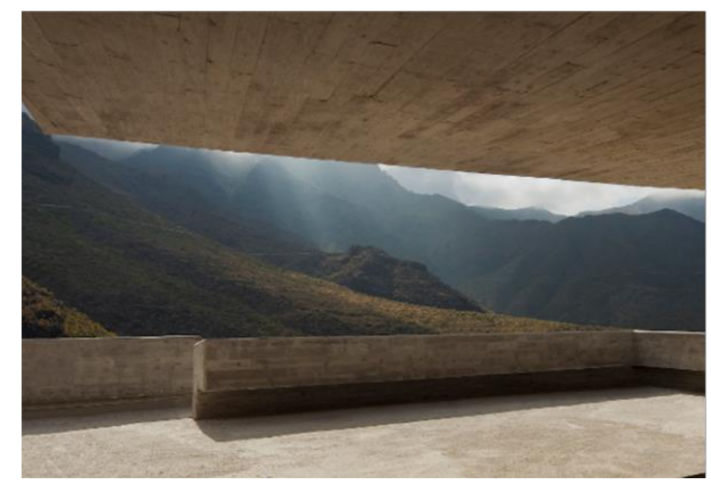

(a)

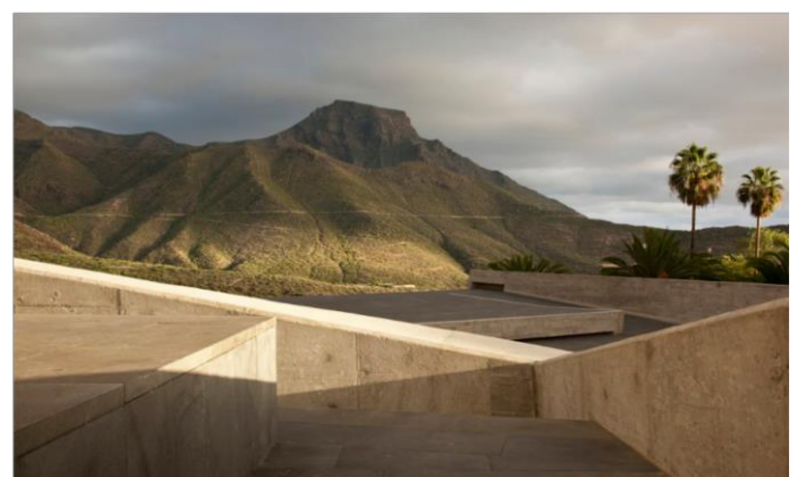

(b)

Figure 4. Square and Sacred Museum, Adeje, Fernando Menis 2007-2010. View of the panoramic square (b) and the belvedere below (a). Photo credit: Simona Rota

From listening to the place, he draws the formal configurations compatible with the landscape. The design process tends to highlight, through architecture, the identity characteristics of the place in which communities can easily recognize themselves. Thus in the CKK Jordanki cultural centre in Torun, Poland (2011-2015), the built volume establishes a harmonious relationship with the natural and built context, thanks to proportions and organic forms that make the building similar to a natural rock set in the slope [48]. Besides that, the new cultural center is related to the cultural context that welcomes it through a new material, experimental, which covers the interior and some "folds" of the external volumes, called picado (Figure 5).

Already introduced in the Holy Redeemer Church in La Laguna, here the material is developed and fine-tuned through a process that has allowed the architectural intervention to anchor further to the place. Picado (a mix of cement, recycled brick fragments, and other materials) represents here the architectural tradition of red brick, so typical in the historical cities of northern Poland. Red bricks characterize almost all the facades of the historic center of Torun (UNESCO site). By imposing this material as an aesthetic and symbolic feature of the building, Menis does nothing more than embed the local essence of the territory into his architecture, while at the same time obtaining excellent acoustic properties in terms of reflection and diffusion of sound, making its use suitable in concert halls [43]. 
In the strategic project for the economic revival of the small village of Burchen in Switzerland, called Burchen Mystik (2013-2015), Menis's proposal for the enhancement of tourism at the site is based on the search for the authenticity of the place, its identity characteristics, not only referring to the historical, cultural, and naturalistic heritage, but also to the importance of living in a community (Figure 6). The program for the new equipment for tourism enhancement is intimately interconnected with the activities of the inhabitants, following an innovative vision in which the tourist of tomorrow is looking for authentic experiences to be enjoyed in freedom, without any mediation or imposed filter. The tourist infrastructure dissolves into the natural landscape and tells the history of the places to those who pass through it. In the small square, the only realization — to date-of the project currently underway, Menis involves the local sawmill, which is in crisis due to regulatory changes that penalize its economic activities. The sawmill was asked to make the benches, which therefore become a showcase for the technical possibilities of wood. Reinterpreting traditional geometries and plastic qualities of this material, it was possible to create new types of sustainable urban furniture that can also be used in other contexts. The idea that architecture can play an economic and social welfare role is also part of landscape sustainability in the broad sense.
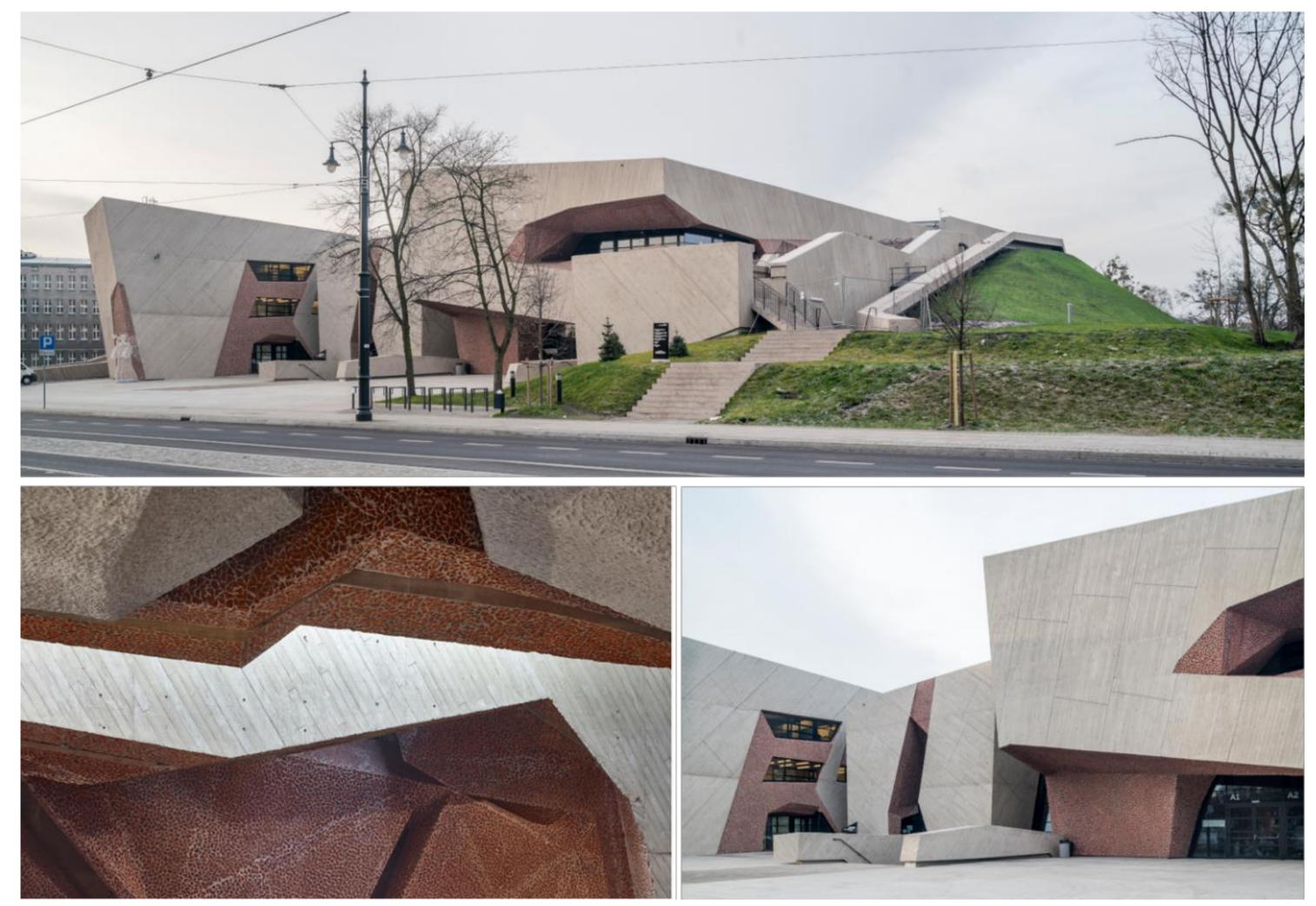

Figure 5. Cultural Center CKK Jordanki, Torun, Fernando Menis 2011-2015. General view and details. Photo credit: Jakub Certowicz. 


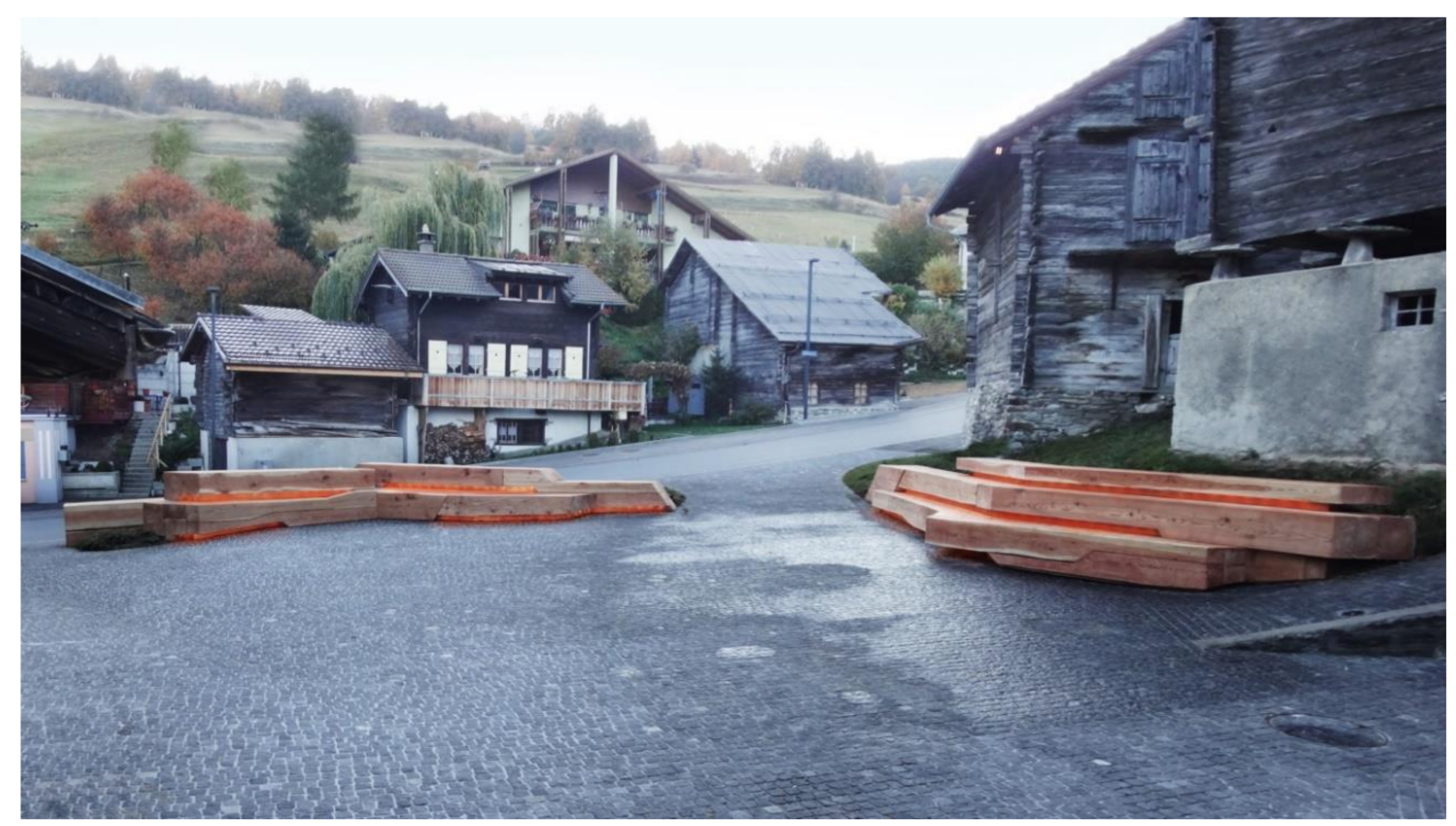

Figure 6. Burchen Mystik, Burchen, Fernando Menis 2013-2015. View of the realized square. Photo credit: Fernando Menis.

\subsection{Architecture and Environment}

Finally, the third and last theme with which the landscape sustainability of Menis's architecture can be declined concerns the environmental dimension of the architectural project. This theme is implicitly present in the tricks and good practices that Menis generally adopts in his projects, but it is radically pushed in some experimental projects with a strong utopian charge, as yet not realized. In these projects, he engages in theoretical speculation useful to give a visionary dimension to the whole of his architectural thought.

His conceptual model of architecture has evolved over time towards an ethic of ecological design, which assumes the abstract configuration of a cube, declined in two variants. The Cool Box project (2011) is an environmental education center in Costa Rica, consisting of a cube entirely made of bamboo measuring $20 \times 20 \times 20 \mathrm{~m}$ in which potentially inhabitable spaces are excavated to house the required functions. The bioclimatic behavior of the building is designed to minimize energy consumption and $\mathrm{CO}_{2}$ emissions, using natural elements such as water and air to help maintain environmental comfort in a totally passive manner.

The Hatching - Molding Nature to Make Life Possible (2014) project is a utopian machine to explore the ability of natural forces to create a life-friendly microclimate in an inhospitable environment. Invited at the Architecture Venice Biennale of 2014 in the Morocco Pavillon, Menis proposes a cubic volume, with a $1 \mathrm{~km}$ long side, imagined in the Sahara Desert. This abstract volume becomes a habitable place, thanks to its ability to capture the fresh and humid winds of the Atlantic Ocean that, eroding the structure, make it porous. The humidity trapped in its meanders favors the growth of vegetation, triggering a water circulation. This water, together with natural ventilation, light, and heat from the sun, contributes to creating a new three-dimensional oasis in the desert, capable of exemplifying the rethinking of a sustainable habitat (Figure 7). A life machine that consumes zero energy, Hatching aims to demonstrate that an architectural structure can produce life through the exclusive use of the forces of nature and the manipulation of forms [43]. 


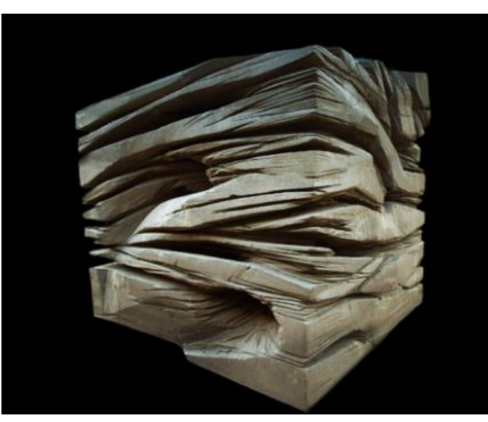

(a)

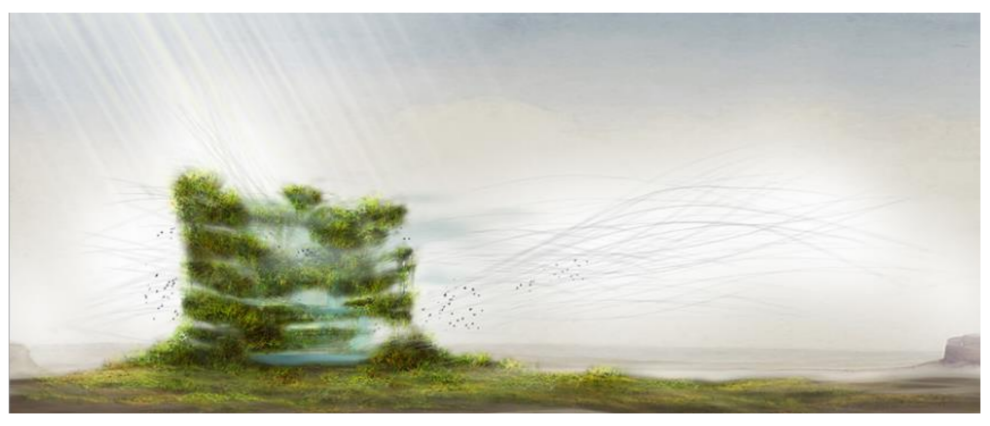

(b)

Figure 7. The Hatching-Molding Nature to Make Life Possible, Fernando Menis 2014. Model (a) and concept drawing (b). Photo credit: Fernando Menis.

\subsection{Key Findings}

The volcanic landscape of his homeland pushes Menis towards a plastic and material architecture. Architecture and volcanic soil are in constant dialogue, favoring the landscape insertion of the built interventions. Landscape sustainability is not limited to the harmonious insertion in the context but extends to the interior architectural space. Through the control of natural light and materials, the atmospheres of Menis's architecture evoke the volcanic landscapes in which they are inserted.

By promoting the local economy and respecting the identity characteristics of the context, Menis's architecture brings other strategies of landscape sustainability into play. Particularly in the field of tourism, the driving sector of the Canarian economy, his projects tend to develop a sustainable infrastructure, capable of opposing the homologation of mass tourism and also responding in an integrated manner to the needs of the inhabitants. The enhancement of the landscape identity and of the user's experience in the field of tourism, together with the combination of local technologies and products with innovative and experimental processes, has enabled Menis to operate with the same approach even in contexts far from its land of origin.

The ecological concerns applied to the spatial plastic approach of Menis's architecture give it a utopian dimension. This is evident in his more daring architectural experimentations, which are at the limit of artistic research.

\section{Conclusions}

The crisis of the modern world and its development models invites us to look to marginal places with respect to the current centers of technological development and economic power in search of new ways of inhabiting the planet that are more human and respectful of the balance between man and nature. It is necessary to develop a greater sensitivity of architecture that foster a concrete alliance between human constructions and the entire living nature. To this end, it is useful to take into consideration the landscape dimension of architecture in order to identify criteria and parameters aimed at assessing the sustainability of built interventions. The landscape sustainability of architecture measures its capacity to build material and immaterial relationships, in time and space, between environment, artifacts and people. Just as landscape sustainability is a multidimensional concept that involves the pursuit of human wellbeing in a global sense and in harmony with ecological processes, so the landscape sustainability of architecture is aimed at the integration of designed spaces, inhabitants and places. Technological skills, in this approach, must be put at the service of a human worldview in harmony with nature; it is a sensitive experience through meaning is granted to reality and an authentic relationship with the simplicity of being in the world is found [4]. The study of Fernando Menis's work, framed in its territorial context of origin, the Macaronesian region, allows us to highlight an approach to architectural design oriented toward multidimensional landscape sustainability, permeated by a strong plastic-tactile sensitivity. 
The landscape sustainability of Menis's work stems from the dialogue with the volcanic ground of its original context and then evolves towards a wider search for relationships and interactions with the identity elements of places. The built architectures interact with the elements of the context, creating new landscapes and topographies. On occasion, architecture imposes itself as a landmark, as a catalyst in a site in search of order; at other times it dissolves into the landscape, to create a "natural city" or a "new cultural topography" [49].

The analysis carried out shows that the design process is mainly based on two key actions:

- Listening to the place, declined in perceptive terms (context characteristics), functional (intervention program), economic (low budget), social (expectations of the settled communities), constructive (choice of technologies), experiential (materials, light, atmospheres).

- The search for sensorial spatiality that can restore, through the experience of architecture, the identity characteristics and atmospheres of the places where the architecture itself is set.

As Luis Fernández-Galiano stated, "Menis's work has known how to go beyond its volcanic and insular precinct to explore faraway sites, pushed by a crisis that has forced many to exit their comfort zones, but also moved by the clear conscience that his formal universe does not end at the archipelago's perimeter." [50] The personal trajectory of Menis's architecture is therefore exemplary for having been able to develop a poetics linked to the place and to export it even in very different contexts, to the point that it can be defined both regional and cosmopolitan [50].

It can be said that Menis's work has reached a maturity of style, in the meaning Monestiroli gives to this term: "Style is the necessary requirement for a work of art to be a promise of happiness. In order for a work to contain a whole world, accomplished and recognizable in itself, it is necessary that a style is achieved: a lasting and stable form, a shared form, in which a better world is glimpsed, in which common feelings are revealed, in which a promise of happiness is manifested. [...] The moments of crisis, and ours is one of them, will be moments in which everyone, in their own way, will contribute to the knowledge of the world. But only when there is a strong convergence between the work of artists and the aspirations of a community will it be possible to speak of style again." [51]

In responding to the questions posed by globalization without losing its essence and without forgetting its roots, Menis's approach shows the potential for a new way of working that imposes the paradoxical concept of "glocal" as a vital necessity to create resilient places of identity [49].

Funding: This research was funded by the University of Catania, in the framework of the "Piano Triennale della Ricerca 2016-2018".

Acknowledgments: I would like to thank Anna Maria Atripaldi for sharing this research and always supporting my interest in the relationship between architecture and volcanic landscape. Photo credits: Figure 1 @ Anna Maria Atripaldi; Figures 2, 6 and 7 (C) Fernando Menis; Figures 3 and 4 (C) Simona Rota; Figure 5 (C) Jakub Certowicz.

Conflicts of Interest: The authors declare no conflict of interest.

\section{References}

1. Kamara, M. Oltre il regionalismo critico. Domus 2020, 1044, 27.

2. Kroll, L. Tout est paysage, une architecture habitée. Original Exposition presented at the Cité de l'Architecture et du Patrimoine, Paris, France, 3 June-14 September 2015.

3. Kroll, L. Interview—Lucien Kroll or the architect without a master. Architecture d'Aujourd'hui 2007, 368, 92-99.

4. Caffo, L. Quattro Capanne o Della Semplicità; Nottetempo: Milano, Italy, 2020.

5. Caffo, L.; Coppola, M. L'architettura del postumano. Domus 2017, 1016, 8-9.

6. Calvagna, S.; Gagliano, A.; Greco, S.; Rodonò, G.; Sapienza, V. Innovative Multidisciplinary Methodology for the Analysis of Traditional Marginal Architecture. Sustainability 2020, 12, 1285. [CrossRef]

7. Rudofsky, B. Architecture Without Architects: A Short Introduction to Non-Pedigreed Architecture; Museum of Modern Art: New York, NY, USA, 1965.

8. Farinelli, F. L'arguzia del paesaggio. Casabella 1991, 55, 575-576. 
9. European Landscape Convention. Florence 2000. Available online: https:/www.coe.int/en/web/landscape/ text-of-the-european-landscape-convention (accessed on 7 September 2020).

10. Zhou, B.; Wu, J.; Anderies, J.M. Sustainable landscapes and landscape sustainability: A tale of two concepts. Landsc. Urban Plan. 2019, 189, 274-284. [CrossRef]

11. Musacchio, L.R. The ecology and culture of landscape sustainability: Emerging knowledge and innovation in landscape research and practice. Landsc. Ecol. 2009, 24, 989-992. [CrossRef]

12. Gregory, P. Teorie di Architettura Contemporanea. Percorsi del postmodernismo; Carocci Editore: Rome, Italy, 2010; p. 33.

13. Poon, S.T.F. Examining the Phenomenology of Human Experience in Design Process and Characteristics of Architectural Approaches. IOP Conf. Ser. Earth Environ. Sci. 2018, 146, 012079. [CrossRef]

14. Wong, J.F. The script of viscosity: The phenomenal experience in Steven Holl's museum architecture. J. Arch. 2012, 17, 273-292. [CrossRef]

15. Yourcenar, M. Memoirs of Hadrian; Penguin: London, UK, 1955.

16. Report of the World Commission on Environment and Development: Our Common Future. Available online: https://sustainabledevelopment.un.org/content/documents/5987our-common-future.pdf (accessed on 7 September 2020).

17. $\mathrm{Wu}, \mathrm{J}$. Landscape sustainability science: Ecosystem services and human wellbeing in changing landscapes. Landsc. Ecol. 2013, 28, 999-1023. [CrossRef]

18. Musacchio, L.R. The scientific basis for the design of landscape sustainability: A conceptual framework for translational landscape research and practice of designed landscapes and the six Es of landscape sustainability. Landsc. Ecol. 2009, 24, 993-1013. [CrossRef]

19. Schweber, L.; Leiringer, R. Beyond the technical: A snapshot of energy and buildings research. Build. Res. Inf. 2012, 40, 481-492. [CrossRef]

20. Fathy, H. Costruire con la Gente; Jaca Book: Milano, Italy, 1986.

21. Calvagna, S.; Finocchiaro, L.; Sapienza, V.; Rodonò, G. Ripensare vernacolare: Per un'architettura tra paesaggio e tettonica. In Patrimonio in Divenire. Conoscere Valorizzare Abitare, Proceedings of REUSO Matera -VII Convegno Internazionale Sulla Documentazione, Conservazione e Recupero del Patrimonio Architettonico e Sulla Tutela Paesaggistica, Matera, Italy, 23-26 October 2019; Conte, A., Guida, A., Eds.; Gangemi Editore International Publishing: Rome, Italy, 2019; pp. 2327-2340.

22. Frey, P. Learning from Vernacular: Towards a New Vernacular Architecture; Actes Sud: Arles, France, 2010.

23. Contal, M.; Revedin, J. Sustainable Design II: Vers Une Nouvelle Éthique Pour l'architecture et la Ville; Actes Sud: Arles, France, 2011; pp. 56-70.

24. Frampton, K. Anti-tabula rasa: Verso un regionalismo critico. Casabella 1984, 500, 22.

25. Norberg-Schulz, C. Genius Loci. Paesaggio Ambiente Architettura; Electa: Milan, Italy, 1992.

26. Ando, T. Shintai et espace. In Tadao Ando: Pensées sur l'Architecture et le Paysage; Nussaume, Y., Ed.; Arléa: Paris, France, 2014; pp. 97-100.

27. Kimmel, L. L'architecture Comme Paysage-Alvaro Siza; Petra: Paris, France, 2010.

28. Kuma, K. Giardinaggio versus architettura. Lotus Int. 1998, 97, 46-63.

29. Farrel, Y.; McNamara, S. Freespace Manifesto. In 16. Mostra Internazionale di Architettura FREESPACE. Guida Breve; La Biennale di Venezia: Venezia, Italy, 2018; pp. 35-36.

30. Arch Daily. Available online: www.archdaily.com (accessed on 13 October 2020).

31. Atlas of Architecture. Available online: divisare.com (accessed on 13 October 2020).

32. Dezeen: Architecture and Design Magazine. Available online: www.dezeen.com (accessed on 13 October 2020).

33. Biancotti, A. Macaronesia. Uomo, Ambiente, Spazio e Territorio Nelle Isole dell'Atlantico Orientale; BEM: Milano, Italy, 2001.

34. Available online: https://whc.unesco.org/en/list/1117/ (accessed on 7 September 2020).

35. Vieira da Silva, I.; Vieira, M. Grotto of Towers, Visitors' Centre, Pico, Azores. Architecture d'Aujourd'hui 2006, $366,72-77$.

36. Labasse, A. Empreintes sur la tradition. Architecture D'aujourd'hui 2013, 395, 59-69.

37. Castellano Pulido, F.J. Living terraces: From reuse in traditional architecture to Cesar Manrique and Souto de Moura's work with me. Proyecto Progreso Arquitectura 2019, 21, 34. [CrossRef] 
38. Calvagna, S. Architettura e natura vulcanica. Architecture and volcanic nature. In Architettura Natura Arte; Atripaldi, A.M., Ed.; Gangemi Editore International Publishing: Rome, Italy, 2017; p. 83.

39. Vercelloni, M. Spazi ipogei. Casabella 2011, 799, 26-55.

40. Atripaldi, A.M.; Calvagna, S. The design of volcanic ground, from disaster to heritage. Architecture and landscape in Macaronesia. In World Heritage and Disaster. Knowledge, Culture and Representation, Proceedings of Le Vie dei Mercanti XV Forum Internazionale, Naples, Italy, 15-17 June 2017; La Scuola di Pitagora Editrice: Napoli, Italy, 2017.

41. Bergdoll, B. Geological Architecture in the Global Age. UED 2017, 106, 52-57.

42. Pizza, A. Residenza universitaria, La Laguna, Tenerife. Domus 1997, 794, 26-31.

43. Menis, F.; Xerach, D. Backstage Fernando Menis; Ediciones Idea: Santa Cruz de Tenerife, Spain, 2018.

44. Cohn, D. L'impronta del Fuoco. In Casabella; Gruppo Mondadori: Milan, Italy, 2002; 706/707, pp. $116-121$.

45. Insular Athletics Stadium/AMP Arquitectos. ArchDaily. 24 June 2008. Available online: https://www. archdaily.com/2822/insular-athletics-stadium-amp-arquitectos-sl \T1\textgreater\{\}ISSN0719-8884 (accessed on 7 September 2020).

46. Menis, F. Botanical garden in La Gomera Island. UED 2017, 106, 136-143.

47. Menis, F. (Ed.) Fernando Menis architect: Reason + Emotion; Actar: Barcelona, Spain, 2008.

48. Menis, F. CKK Jordanki auditorium, Torun, Poland. Arca Int. 2016, 130, 42-51.

49. Zhu, J. Fernando Menis: Towards an Ecological Design Ethics. UED 2017, 106, 46-47.

50. Fernández-Galiano, L. Música calcinada. Music in Flames. Arquit. Viva Monogr. 2016, 181, 3.

51. Monestiroli, A. La Metopa e il Triglifo; Laterza: Milano, Italy, 2002; pp. 116-117.

Publisher's Note: MDPI stays neutral with regard to jurisdictional claims in published maps and institutional affiliations. 